\title{
AKTIVITAS WISATA SPIRITUAL DAN MOTIVASI BERWISATA DI DAYA TARIK WISATA TANAH LOT KABUPATEN TABANAN
}

I Gusti Agung Riza Dwi Kusuma a, 1, Ida Ayu Suryasih a, 2

1 riza.kusuma1994@gmail.com, ${ }^{2}$ iasuryasih@yahoo.com

a Program Studi S1 Destinasi Pariwisata,Fakultas Pariwisata,Universitas Udayana, Jl. Dr. R. Goris, Denpasar, Bali 80232 Indonesia

\section{ABSTRACT}

Research on the factors that motivate tourists visiting Tourist Attraction Tanah Lot, who lifted the title "Spiritual Tourism Activity and Motivation Traveled in Tourist Attractions Tanah Lot Tabanan Regency" The purposes of this study are to what the motivation a tourist's visited Tanah Lot.

Data collection techniques in this research, by observation, as many as 65 pieces distributing questionnaires to the respondents, and documentation of studies by taking a picture Tourist Attraction in the area of Tanah Lot. The data have been obtained were analyzed using the technique of data tabulation. Tabulation is the process of placing the data in tabular form by making a table that contains data in accordance with the needs analysis. Tables are made should be able to summarize all the data to be analyzed.

Results from this research is in addition to be a place for traveling because it has beautiful scenery, Tourist AttractionsTanah Lot also many tourists who make it as a place for Spiritual Tourism activities as the main products in Tanah Lot is building his Temple. From the results of questionnaires distributed at the time of the research results obtained include: Other than for the purpose of fun, tourists who come in large part dominated by their curiosity to get to know the local culture and local wisdom of people want to know, in addition to the tourists there are also very enthusiastic in doing the Spiritual Tourism activities in Tanah Lot, they have a strong interest in conducting Spiritual Tourism, because there are a variety of benefits that we can while doing activities The Spiritual Tourism them feel more calm, comfortable, and peaceful.

KeyWords : Motivation, Spiritual Tourism, Traveller, Tanah Lot

\section{PENDAHULUAN}

\subsection{Latar Belakang}

Bali merupakan salah satu provinsi di Indonesia yang memiliki potensi pariwisata yang besar. Provinsi Bali banyak sekali memiliki daya tarik wisata yang memotivasi wisatawan untuk datang berkunjung mulai dari alam (nature), budaya (culture) , kerajinan , kuliner, dan reksreasi. Sebagai suatu Derah Tujuan Wisata, potensi kepariwisataan di Provinsi Bali memiliki daya tarik yang cukup kuat bagi kunjungan wisatawan, baik wisatawan nusantara maupun mancanegara. Belakangan ini di Bali pengembangan wisata spiritual mulai banyak diwacanakan. Bahkan ada yang memprediksikan wisata spiritual akan segera 'booming' dalam beberapa tahun ke depan. Pariwisata spiritual merupakan salah satu pariwisata alternatif yang mulai digalakkan oleh pemerintah. World Travel \& Tourism Review menyatakan pariwisata alternatif merupakan upaya menjauh dari pendekatan pariwisata massal ke pendekatan di mana pengalaman wisata yang lebih khusus ditawarkan dengan cara yang lebih pribadi dan peka secara budaya (Naisbitt, 1994:136). Rencana pengembangan wisata spiritual sempat merebak di banyak kawasan, baik itu Kabupaten Karangasem, Bangli, Buleleng, atau yang lainnya.

Kabupaten Tabanan merupakan salah satu dari 9 kabupaten/kota di wilayah propinsi Bali yang dibentuk berdasarkan UU Nomor 69 Tahun 1958. Kabupaten Tabanan memiliki ekosistem pegunungan, danau, lembah, dataran rendah dan pesisir laut. Potensi yang dimiliki Kabupaten Tabanan menyebabkan telah berkembangnya sektor pariwisata di Bali. Kabupaten Tabanan memiliki potensi yang baik untuk melakukan aktivitas Wisata Spiritual karena adanya keberadaan dari daya tarik wisata Tanah Lot.

Tanah Lot terletak di Desa Beraban Kecamatan Kediri yang berjarak \pm 13 KM dari Kota Tabanan. Tanah Lot merupakan salah satu daya tarik wisata alam yang digemari oleh wisatawan nusantara maupun mancanegara. Yang menjadi Potensi utama pada tempat ini yaitu Arsitektur Bangunan Puranya. Lokasi Pura ini sangatlah unik karena berbeda dari lokasi Pura sebagaimana biasanya. Pura ini berada di tengah bongkahan batu yang besar dan terletak di tengah Laut. Dengan keunikannya tersebut menjadikan daya tarik wisata Tanah Lot selalu ramai dikunjungi wisatawan. Tidak hanya itu saja, di tempat ini juga mereka dapat melihat ular suci yang dipercaya merupakan penjelmaan 
dari selendang Danghyang Nirartha saat ingin meninggalkan Tanah Lot. Selain bertujuan untuk berwisata, ditempat ini pula wisatawan juga dapat melakukan aktivitas Wisata Spiritual seperti Berdoa maupun melakukan Pembersihan diri (Malukat). Tanah Lot juga dipercaya sebagai tempat untuk pemujaan Dewa-Dewa penjaga laut.

Dari tahun ke Tahun jumlah wisatawan yang berkunjung ke daya tarik wisata Tanah Lot mengalami peningkatan. Berdasarkan Sumber dari Manajer Operasional daya tarik wisata Tanah Lot yang dipublikasikan melalui www.antarabali.com disebutkan bahwa pada bulan April 2015 jumlah kunjungan wisatawan Nusantara dan Mancanegara mencapai 247.377 orang dibandingkan dengan tahun sebelumnya pada periode yang sama hanya 237.045 orang. Wisatawan anak-anak nusantara sebanyak 3.170 orang, 135.464 orang untuk dewasa nusantara, 2609 untuk anak anak mancanegra dan 95.082 untuk dewasa mancanegara. Maka dari itu penelitian ini dilakukan untuk mengetahui motivasi wisatawan mengunjungi daya tarik wisata Tanah Lot.

\section{Rumusan Masalah}

Berdasarkan latar belakang di atas maka dapat dirumuskan permasalahan yaitu,

1. Apa motivasi umum wisatawan dalam berwisata ke daya tarik wisata Tanah Lot?

2. Apa motivasi khusus wisatawan dalam melakukan aktivitas Wisata Spiritual di daya tarik wisata Tanah Lot?

\section{Tujuan Penelitian}

Berdasarkan rumusan masalah diatas maka tujuan penelitiannya adalah :

1. Untuk mengetahui motivasi umum wisatawan dalam berkunjung ke daya tarik wisata Tanah Lot.

2. Untuk mengetahui motivasi wisatawan dalam melakukan aktivitas Wisata Spiritual di daya tarik wisata Tanah Lot.

\section{KEPUSTAKAAN}

\section{Landasan Konsep dan Teori}

\section{Daya Tarik Wisata}

Daya tarik wisata adalah segala sesuatu yang memiliki keunikan, keindahan, dan nilai yang berupa keanekaragaman kekayaan alam, budaya, dan hasil buatan manusia yang menjadi sasaran atau tujuan kunjungan wisatawan. (Undang-Undang
Kepariwisataan no. 10 tahun 2009) daya tarik wisata yang dimaksud dalam penelitian ini adalah daya tarik wisata Tanah Lot

\section{Wisatawan}

Wisatawan adalah orang yang melakukan wisata. Sedangkan menurut Smith dalam (Kusumaningrum, 2009), menjelaskan bahwa wisatawan adalah orang yang sedang tidak bekerja, atau sedang berlibur dan secara sukarela mengunjungi daerah lain untuk mendapatkan sesuatu yang lain

\section{Wisata Spiritual}

Spiritual Tourism juga disebut dengan Meditation Tourism yaitu wisatawan diajak ke suatu tempat, umumnya pura untuk melakukan kegiatan meditasi. Menurut klasifikasi umum, spiritual tourism atau meditasi tourism dapat dimasukkan sebagai salah satu bentuk culture tourism, karena unsur budaya sangat kental dalam kegiatan meditasi, sama seperti wisatawan mengunjungi pura, juga termasuk culture tourism, karena Pura adalah salah satu bentuk hasil karya manusia. ( Pitana, 2002 )

\section{Motivasi Pariwisata}

Teori Motivasi oleh Mcintoch, Goeldner dan Ritchie (1995) menyebutkan bahwa motivasi dalam pariwisata meliputi :

1. Motivasi untuk memenuhi kebutuhan fisik

2. Motivasi untuk mengenal budaya

3. Motivasi untuk berhubungan dengan orang lain

4. Motivasi untuk memperoleh status dan prestise

Konsep ini nantinya akan digunakan untuk mengetahui faktor apa yang lebih mendominasi wisatawan untuk berkunjung ke daya tarik wisata Tanah Lot

\section{Motivasi Wisata Spiritual}

Motivasi Wisata Spiritual Menurut Mckercher dalam (Haq and Jackson 2006:2) yaitu :

1. Purposeful Spiritual Tourist

2. Sightseeing Spiritual Tourist

3. Casual Spiritual Tourist

4. Incidental Spiritual Tourist

5. Serendipitous Spiritual Tourist

Konsep ini nantinya akan digunakan untuk 
mengetahui faktor apa yang lebih mendominasi wisatawan untuk melakukan kegiatan Wisata Spiritual di daya tarik wisata Tanah Lot

\section{METODOLOGI PENELITIAN}

\section{Lokasi Penelitian}

Penelitian ini berlokasi di daya tarik wisata Tanah Lot. Dipilihnya Tanah Lot sebagai lokasi penelitian karena Tanah Lot merupakan salah satu destinasi wisata yang memiliki jumlah kunjungan wisatawan yang meningkat setiap tahunnya dan memiliki panorama alam yang indah, Selain itu daya tarik wisata Tanah Lot merupakan salah satu Destinasi di Kabupaten Tabanan yang merupakan tujuan wisatawan untuk berwisata maupun melakukan kegiatan Wisata Spiritual

\section{Ruang Lingkup Penelitian}

Guna memperjelas dan membatasi ruang lingkup penelitian ini maka secara operasional variable yang terdapat dalam permasalahan yang dibahas yaitu :

1. Motivasi wisatawan dalam melakukan aktivitas Wisata Spiritual di daya tarik wisata Tanah Lot. Motivasi ini tentunya digolongkan menjadi 5 jenis menurut Mckercher dalam (Haq and Jackson 2006) yaitu :

a. Minat yang kuat ditambah dengan pengetahuan yang ada dalam melakukan kegiatan spiritual

b. Minat yang kuat namun kurangnya pengalaman dalam melakukan kegiatan spiritual

c. Melakukan kegitan spiritual karena menjadi trend saat ini.

d. Ketidaksengajaan ikut serta dalam kegiatan spiritual selama berwisata.

e. Terdapat manfaat yang didapat setelah melakukan kegiatan spiritual

2. Motivasi wisatawan dalam berwisata ke daya tarik wisata Tanah Lot. Motivasi ini tentunya digolongkan menjadi 4 jenis menurut Mcintoch, Goeldner dan Ritchie (1995) yaitu :

a) untuk tujuan bersenang -senang

b) untuk mengenal budaya setempat

c) untuk berinteraksi dan mencari pengalaman baru

d) untuk peningkatan status/prestise dalam lingkungan masyarakat

\section{Teknik Pengumpulan Data}

Teknik Pengumpulan Data dalam penelitian ini dilakukan dengan cara :

(1) Observasi, dalam penelitian ini observasi dilakukan dengan mengunjungi atau melakukan pengamatan langsung ke Pura Tanah Lot sehingga dapat melihat langsung keadaan lokasi penelitian. (2). Dokumentasi, dalam penelitian ini dokumen yang digunakan adalah Foto-Foto Pura Tanah Lot seperti bangunan Pura, serta foto wisatawan yang sedang berwisata atau sedang melakukan kegiatan wisata spiritual. (3). Kuisioner dalam penelitian ini kuisioner yang disebar sebanyak 65 buah, yang dibagi menjadi 2 yaitu 35 buah kuisioner untuk wisatawan nusantara dan 30 buah kuisioner lainnya untuk wisatawan macanegara.

\section{Teknik Penentuan Sampel}

Metode penentuan sampel dari wisatawan dilakukan dengan pendekatan Nonprobabillity Sampling melalui metode convenience sampling. Dengan menggunakan teknik pengambilan sampel berupa Insidental Sampling. Sampel adalah bagian dari populasi yang mempunyai ciri- ciri atau keadaan tertentu yang akan diteliti (Riduwan, 2008). Insidental Sampling adalah teknik pengambilan sampel berdasarkan kebetulan, yaitu siapa saja yang secara kebetulan / incidental bertemu dengan peneliti yang dapat digunakan sebagai sampel, bila dipandang orang yang kebetulan ditemui cocok sebagai sumber data (Sugiyono, 201 : 85). Dalam Ukuran sampel yang diambil mengacu pada metode Slovin dengan rumus :

$$
\begin{aligned}
& \mathrm{n}=\mathrm{N} \\
& =182 \\
& \quad 182 \overline{(0,1)^{2}+1} \\
& =64,5 \text { jumlah sampel } \\
& \text { Maka dari itu di dapat jumlah sampel } \\
& \quad \text { sebanyak } 65 \text { orang }
\end{aligned}
$$

\section{Teknik Analisis Data}

Analisis yang dipergunakan dalam penelitian ini adalah analisis deskriptif kualitatif. (Bodgan dan Biklen dalam Moleong, 2012). Selain menggunakan penelitian kualitatif, penelitian ini juga menggunakan penelitian kuantitatif maka data yang terdiri dari angka-angka dapat di analisis berdasarkan prosedur statistik. Untuk 
mempermudah menganalisis data, maka dipergunakan sistem tabulasi data.

\section{HASIL DAN PEMBAHASAN}

\section{Motivasi umum wisatawan dalam berkunjung ke daya tarik wisata Tanah Lot}

Tanah Lot merupakan Suatu daya tarik yang tidak pernah lepas dari kunjungan wisatawan. Tentunya terdapat berbagai alasan yang memotivasi wisatawan ingin berkunjung ke tempat ini. Maka dari itu untuk melihat apa yang memotivasi wisatawan berkunjung ke tempat ini. Dalam penelitain ini motivasi wisatawan dalam berkunjung ke Tanah Lot beragam diklasifikasikan menjadi 4 jenis kategori yaitu (1) Untuk tujuan bersenangsenang, (2) Untuk mengenal budaya setempat , (3) Untuk berinteraksi dan mencari pengalaman baru dan (4) Untuk peningkatan status/ prestise dalam lingkungan masyarakat. Faktor yang memotivasi wisatawan dalam berkunjung ke Tanah Lot dapat dilihat sebagai berikut :

Dari jumlah Kuisioner yang disebar sebanyak 65 buah di daya tarik wisata Tanah Lot, maka di dapat hasil bahwa jumlah kunjungan wisatawan sebesar 59 orang dengan persentase sebanyak $(90,8 \%)$ lebih dominan memilih untuk mengenal budaya setempat. Dari hasil survey yang dilakukan pada saat itu, kebanyakan yang memilih untuk mengenal budaya setempat adalah mayoritas dari wisatawan mancanegara, hal ini dikarenakan bahwa wisatawan mancanegara sangat antusias untuk mengenal dan memiliki rasa keingintahuan yang tinggi tentang budaya yang ada di Tanah Lot serta ingin mengetahui kearifan lokal masyarakatnya, seperti saat melakukan observasi dilapangan pada saat penelitian diketahui bahwa banyak terlihat wisatawan mancanegara yang bercengkrama dengan masyarakat lokal tentang kegiatan piodalan yang ada di Tanah Lot pada waktu itu. Mereka sendiri ingin tahu apa makna yang terkandung dari piodalan tersebut. Selain itu mereka juga mengabadikan momen kegiatan piodalan tersebut dengan kamera yang mereka bawa, karena hanya disini saja mereka bisa melihat kegiatan tersebut, sedangkan di Negara mereka masih jarang terdapat kegiatan semacam ini. Dari jumlah kunjungan wisatawan sebesar 56 orang dengan persentase $(86,2 \%)$ memilih untuk bersenang-senang, karena mereka ingin melepaskan diri dari kejenuhan dan rutinitas yang mereka lakukan sehari-hari serta untuk meningkatkan experience atau mencari pengalaman baru. Biasanya mereka menikmati pemandangan pantai yang indah sambil berfoto bersama keluarga maupun teman teman mereka, dan jika saat sore tiba, wisawatan biasanya berada di Sunset Terrace, dimana tempat ini merupakan salah satu tempat favorit wisatawan untuk menikmati Sunset sambil mencicipi wisata kuliner. Dan hanya 21 orang wisatawan dengan persentase sebesar $(32,3 \%)$ memilih datang berkunjung ke Tanah Lot Untuk peningkatan status/ prestise dalam lingkungan masyarakat.

\section{Motivasi khusus wisatawan dalam melakukan aktivitas Wisata Spiritual di daya tarik wisata Tanah Lot}

Selain sebagai tempat untuk berwisata, daya tarik wisata Tanah Lot juga difungsikan sebagai tempat untuk aktivitas Wisata Spiritual, hal ini dikarenakan core produk utama dari Tanah Lot merupakan Bangunan Pura nya. Maka dari itu dalam penelitian ini . Faktor yang memotivasi wisatawan dalam melakukan kegiatan Wisata Spiritual ke Tanah Lot dapat dilihat sebagai berikut :

Dari jumlah Kuisioner yang disebar sebanyak 65 buah di daya tarik wisata Tanah Lot, maka di dapat hasil bahwa dalam melakukan aktivitas Wisata Spiritual, sebesar 33 orang dengan presentase sebanyak (50,8\%) berpendapat bahwa mereka memiliki minat yang kuat namun pengalaman mereka sangat kurang dalam mengikuti kegiatan spiritual. namun setelah mereka melakukan kegiatan wisata spiritual di Tanah Lot, mereka mendapatkan berbagai manfaat pengalaman yang paling kuat dalam berwisata. Berbagai manfaat yang mereka dapatkan setelah melakukan kegiatan wisata spiritual yaitu mereka merasa lebih tenang, nyaman, damai dan juga menambah pengalaman baru bagi wisatawan mancanegara khusunya dalam melaksanakan kegiatan Wisata Spiritual. Selain itu dengan adanya kegiatan Wisata Spiritual ini , secara tidak langsung tentunya hal ini merangsang terjadinya interaksi sosial antara masyarakat dengan wisatawan. Interaksi sosial yang terjadi dapat membuka wawasan masyarakat untuk memperkenalkan 
kebudayaan lokal kepada wisatawan ,sehingga wisatawan tidak hanya sekedar berwisata melainkan juga mendapat pengetahuan tentang kebudayaan yang ada di Bali Sedangkan sebanyak 10 orang dengan presentase 15,4\% memilih kegiatan spiritual karena menjadi trend saat ini, hal ini dikarenakan bahwa dengan melakukan aktivitas Wisata Spiritual tentunya dapat meningkatkan Prestige mereka dimata Masyarakat.

\section{SIMPULAN DAN SARAN \\ 5.1. Simpulan}

Dari Penelitian ini dapat disimpukan bahwa Motivasi wisatawan dalam berkunjung ke Tanah Lot diketahui dari jumlah kunjungan wisatawan tertinggi (sebesar 59 orang dengan presentase 90,8\%) memilih untuk mengenal budaya setempat karena memiliki rasa keingintahuan tentang budaya yang ada di Tanah Lot dan ingin mengetahui kearifan lokal masyarakatnya. Jumlah kunjungan wisatawan berdasarkan motivasi spiritualnya tertinggi (sebesar 33 orang dengan presentase 50,8\%) berpendapat bahwa memiliki minat yang kuat tetapi pengalaman dalam melakukan kegiatan spiritual masih kurang serta ketidaksengajaan wisatawan dalam melakukan wisata spiritual, namun setelah mereka melakukan kegiatan wisata spiritual, mereka mendapatkan pengalaman yang paling kuat dalam berwisata.

\subsection{Saran}

Saran yang bisa diberikan untuk pengelola adalah untuk menyediakan Guide Lokal yang tentunya memiliki pemahaman yang luas terhadap Tanah Lot. Guide Lokal ini nantinya akan memberikan informasi informasi di daya tarik wisata Tanah Lot kepada wisatawan, sehingga wisatawan yang datang tidak hanya sekedar berwisata, tetapi juga mereka mendapat ilmu dan pengetahuan terhadap suatu tempat yang mereka kunjungi.

\section{DAFTAR PUSTAKA}

Anonim.2009.Undang-undang Republik Indonesia No.10 tahun 2009 Kepariwisataan

Budiastawa, I Gede Putu 2009. “Wisata Eko-Spiritual sebagai Alternatif Pengembangan Bukit Bangli di Kabupaten Bangli".

Bodgan \& Biklen Dalam Lexy J. Moleong. Analisis Data, $2012: 248)$

Cooper,D.R.dan Emory, C.W. (1995). Business Research Methods. US : Irwin
Haq, F. dan Jackson, J. 2006. Exploring Consumer Segments and Typologies of Relevance to Spiritual Tourism. Queensland: Central Queensland University. [ cited 25 September 2008]. Available from: http://smib.vuw.ac.nz:808/www.ANZMAC2006/ documents/Haq Farooq.pdf ( 27 Juni 2015 )

Karyono, A. 1997. Kepariwisataan, PT. Grasindo. Jakarta

Pitana. 2002. Apresiasi Kritis Terhadap Kepariwisataan Bali. Denpasar

Pendit. Nyoman S.1994. Ilmu Pariwisata Sebuah Pengantar. Perdana. Jakarta

Soekadijo, R.G. 2000. Anatomi Pariwisata. Jakarta : PT. Gramedia Pustaka Utama

Sugiyono. 2010. Metode Penelitian Kuantitatif, Kualitatif dan R\&D. Bandung : Alfabeta

Sukardi, Nyoman.1998.Pengantar Pariwisata.STP Nusa Dua Bali

Surendro, Bambang. 2012 "Perlindungan Abrasi Pantai Akibat Gelombang di Tanah Lot Bali"

Sutarya, I Gede. 2001. Puspanjali 80 Tahun Ibu Gedong Bagoes Oka ( Membangun Peradaban Baru). Denpasar : Gandhi Puri \& Ahimsa Fund

Titib, I Made. 2006. Wisata Ritual dan Spiritual : Bagaimana Cara Mengemasnya Paper. Matrikulasi Program Studi Kajian Pariwisata, Universitas Udayana Denpasar, 31 Agustus 2006.at Ruang Pasca Sarjana Univ Udayana Jl. PB Sudirman Denpasar 